\title{
Electrodeposition of quaternary alloys in the presence of magnetic field
}

\author{
Mehdi Ebadi, Wan Jeffrey Basirun, Yatimah Alias, Mohammadreza Mahmoudian
}

\begin{abstract}
Electrodeposition of Ni-Co-Fe-Zn alloys was done in a chloride ion solution with the presence and absence of a Permanent Parallel Magnetic Field (PPMF). The PPMF was applied parallel to the cathode surface. The deposition profile was monitored chronoamperometrically. It was found that the electrodeposition current was enhanced in the presence of PPMF (9 T) compared to without PPMF. The percentage of current enhancement ( $\Gamma \%)$ was increased in the presence of PPMF, with results of $\Gamma \%=11.9 \%, 16.7 \%$ and $18.5 \%$ at $-1.1,-1.2$ and $-1.3 \mathrm{~V}$ respectively for a $2400 \mathrm{sec}$ duration. In chronoamperometry, the Composition Reference Line (CRL) for Ni was around 57\%, although the nobler metals (i.e. $\mathrm{Ni}, \mathrm{Co}$ ) showed anomalous behaviour in the presence of $\mathrm{Zn}$ and Fe. The anomalous behaviour of the Ni-Co-Fe-Zn electrodeposition was shown by the Energy Dispersive X-Ray (EDX) results. From Atomic Force Microscopy (AFM) measurements, it was found that the surface roughness of the Ni-Co-Fe-Zn alloy films decreased in the presence of a PPMF.
\end{abstract}

\section{Background}

Alloy electrodeposition of two or more metals has been investigated to examine properties such as grain size, hardness, and corrosion resistance in relation to the parent metals. For example, the electrodeposition of $\mathrm{Zn}$ with iron group elements (i.e. $\mathrm{Fe}, \mathrm{Ni}, \mathrm{Co}$ ) is applied mostly as finishing layers.

Brenner [1] has classified the alloy electrodeposition of $\mathrm{Zn}$ with the iron group elements. The main problem with alloy electrodeposition is the anomalous behavior exhibited during the electrodeposition process. For instance, the Zn-iron group alloys face the problem of anomalous behavior where the less noble metal (i. e. $\mathrm{Zn}$ ) is preferentially deposited compared to the more noble metals in the order $\mathrm{Ni}>\mathrm{Co}>\mathrm{Fe}$. Several theories have been developed [2-4] to explain this anomalous behavior. Dahm and Caroll [5] attribute the anomalous behavior to the Hydroxide Suppression Mechanism (HSM). Their theory suggests that the more noble ions are hindered from electrodeposition by formation of hydroxides of the less noble ions. This theory is further based on the solubility constant $\left(\mathrm{K}_{\mathrm{sp}}\right)$ of $\mathrm{M}(\mathrm{OH})_{2}$ that the $\mathrm{K}_{\mathrm{sp}}$ of $\mathrm{Zn}<\mathrm{Fe}<\mathrm{Co}<\mathrm{Ni}$.

\footnotetext{
* Correspondence: mehdi_2222002@yahoo.com

Department of Chemistry, Faculty of Science, University of Malaya, 50603 Kuala Lumpur, Malaysia
}

Some investigators $[6,7]$ have found that the $\mathrm{pH}$ value in the vicinity of the cathode was increased during alloy electrodeposition, while others [8-10] have disagreed with those results. Several investigators $[7,8,11,12]$ have examined and explored this anomalous behavior by studying the $\mathrm{pH}$, current density, potential range and temperature and its relevance to the anion concentration in the electrolyte. According to some, the electrodeposition rate of the more noble ions rise with the increase of $\mathrm{pH}$ of the electrolyte $[6,13]$. This anomalous behavior during electrodeposition diminishes with rising temperature [7]. In addition to the use HSM theory to explanation above, some authors $[8-10,14,15]$ found that the Under Potential Deposition (UPD) of less noble ions can also lead to the above anomalous electrodeposition. At low potential, normal co-deposition takes place, whereas with increasing potential, anomalous co-deposition occurs [16]. The anions present also affect the pattern of UPD. For instance increasing the concentration of $\Gamma$ in the zinc electrolyte the peak of the $\mathrm{Zn}$ electrodeposition curve shifts to a more negative value in the voltammogram, whereas with increasing $\mathrm{PO}_{4}{ }^{3-}$ shifts the peak in the positive direction along the potential axis [12].

Mass transport in the electrodeposition of ions on the electrode surface can be controlled through diffusion, ionic migration and convection (natural and forced). 
When a Permanent Parallel Magnetic Field (PPMF) is applied parallel to the cathode surface, additional forces such as the Paramagnetic Force $\left(\vec{F}_{P}\right)$, Field Gradient Force $\left(\vec{F}_{B}\right)$, Lorentz Force $\left(\vec{F}_{L}\right)$, Electrokinetic Force $\left(\vec{F}_{E}\right)$ and the Magnetic Damping Force $\left(\vec{F}_{M}\right)$ increase of rate of transport of ions to the electrode surface, thus increasing the mass transport current of the electrode reaction. This effect is also known as the MagnetoHydrodynamic (MHD) which is largely the result of the Lorentz force [17].

The interaction of the magnetic field aligned parallel to the cathode surface with the current flow to the cathode surface results in the Lorentz Force $\left(\vec{F}_{L}\right)$. According Hinds et. al. [17], the Lorentz force $\left(\vec{F}_{L}=\vec{j} \times \vec{B}\right)$, has the largest contribution among all the of forces present in the MHD effect towards the mass transport increase. The influence of magnetic field on the motion of ions and the thickness reduction of the diffusion layer is schematically depicted in Fig. 1.

It is observed that the normal diffusion layer thickness $\delta_{0}$ could be diminished to a narrow layer of $\delta_{\mathrm{D}}$, when the magnetic flux $\mathrm{B}$ was aligned parallel to the cathode surface.

Therefore the MHD effect, (largely caused by the Lorentz Force) reduces the diffusion layer thickness, thus increasing the mass transport to the electrode surface. This work examines and characterizes the electrodeposition of $\mathrm{Ni}-\mathrm{Co}-\mathrm{Fe}-\mathrm{Zn}$ alloys with the presence and absence of a PPMF to the cathode surface.

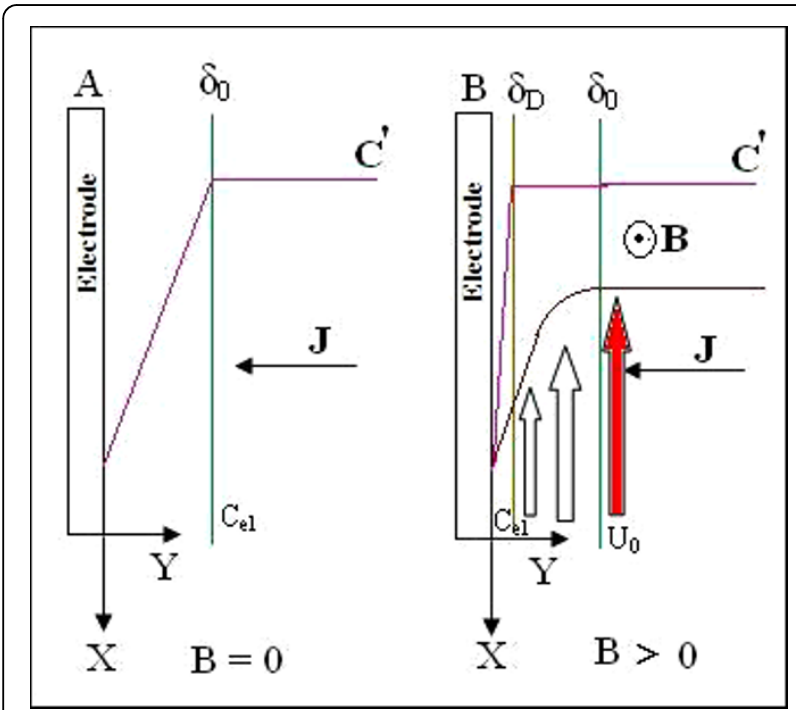

Figure 1 Schematic illustration of the mechanism of enhanced mass transport of charged electroactive species under an applied magnetic field. where the $C_{e l}$ is the surface concentration of electroactive spesies, $C^{\prime}$ the bulk concentration, $B$ the magnetic flux, J the direction of electrical curent, $\mathrm{U}_{0}$ the natral convection, $\delta_{\mathrm{D}}$ and $\delta_{0}$ the boundry layer thickness in the presence and absence of a magnetic field, respectively.

\section{Experimental}

All experiments were carried out in aqueous electrolyte. Copper plates $(0.01 \times 1 \times 1 \mathrm{~cm})$ were used as working electrodes. Each was electrochemically polished and activated by immersion into mixed acids $\left(\mathrm{HCl} 30 \%-\mathrm{H}_{2} \mathrm{SO}_{4}\right.$ $\left.10 \%-\mathrm{HNO}_{3} 5 \%-\mathrm{CrO}_{3} 3 \%\right)$ for a few seconds and then rinsed with double distilled water. The chloride plating solution for the $\mathrm{Ni}$-Co-Fe- $\mathrm{Zn}$ alloys electrodeposition via chronoamperometry contained: $\mathrm{NiCl}_{2} \cdot 6 \mathrm{H}_{2} \mathrm{O} 1 \mathrm{M}$, $\mathrm{CoCl}_{2} \cdot 6 \mathrm{H}_{2} \mathrm{O} 0.25 \mathrm{M}, \mathrm{FeCl}_{2} \cdot 4 \mathrm{H}_{2} \mathrm{O} 0.25 \mathrm{M}, \mathrm{ZnCl}_{2} 0.25 \mathrm{M}$, and $\mathrm{H}_{3} \mathrm{BO}_{3} 0.5 \mathrm{M}$ in the Teflon $(4 \times 8 \times 12 \mathrm{~cm})$. The electrolyte was free from additives such as levellers and brighteners. The electrolyte was kept at room temperature and the $\mathrm{pH}$ was adjusted to $4 \pm 0.1$ with hydrochloric acid. In addition, solutions for cyclic-voltammetery experiments were prepared from $0.01 \mathrm{M}$ each of $\mathrm{Ni}^{2+}$, $\mathrm{Co}^{2+}, \mathrm{Fe}^{2+}, \mathrm{Zn}^{2+}$ ions. The $\mathrm{CV}$ and electrodeposition via chronoamperometry was done using Princeton Applied Research (PAR) Versa-Stat3 instrument in the absence and presence of the Permanent Parallel Magnetic Field (PPMF) of 9 Tesla. All experiments were conducted at temperature $30-32^{\circ} \mathrm{C}$. The Saturated Calomel Electrode (SCE) and platinum wire were the reference and counter electrodes respectively. The topography of the deposited layers was investigated via Atomic Force Microscopy (AFM PS 3000-NS3a). The mass of electrodeposition was determined by the mass difference of the bare and coated $\mathrm{Cu}$ plates. Scanning Electron Microscopy (SEMFEI Quanta 200F) was used to capture images of the surface morphology of the electrodeposited samples and it included the Energy Dispersive X-Ray (EDX) analysis using Energy Dispersive System INCA energy 400.

\section{Results and Discussion}

Voltammetery and Chronoamperometry

Fig. 2 shows the voltammograms of the $\mathrm{Ni}, \mathrm{Co}, \mathrm{Fe}, \mathrm{Zn}$, $\mathrm{Ni}-\mathrm{Co}, \mathrm{Ni}-\mathrm{Co}-\mathrm{Fe}, \mathrm{Ni}-\mathrm{Co}-\mathrm{Zn}$ and $\mathrm{Ni}-\mathrm{Co}-\mathrm{Fe}-\mathrm{Zn}$ in the presence and the absence a PPMF (9 T). The concentration of each ions in the solutions was $0.01 \mathrm{M}$. Fig. 2A$2 \mathrm{D}$ shows that the potential of electro-reduction decrease in the order $\mathrm{Co}^{2+}>\mathrm{Ni}^{2+}>\mathrm{Fe}^{2+}>\mathrm{Zn}^{2+}$ to more negative potentials, where the standard potentials are given as $-0.28 \mathrm{~V},-0.23 \mathrm{~V},-0.44 \mathrm{~V}$ and $-0.76 \mathrm{~V}$ respectively. The influence of a magnetic field applied parallel to the cathode surface is shown in Fig. $2 \mathrm{~A}-2 \mathrm{H}$. The potential of the electro-reduction of the ions did not change with and without the PPMF, but the current increased a little with the application of PPMF. From the Navier-Stokes equation, it can be seen that [18]:

$$
j_{l}=\left(4.3 \times 10^{3}\right) n^{3 / 2} A^{3 / 4} D \cdot v^{-1 / 4} C^{4 / 3} B^{1 / 3}
$$

where $j_{l}$ is limiting current, $v$ the viscosity of the solution, $\mathrm{C}$ the bulk concentration of electroactive species, $\mathrm{B}$ 


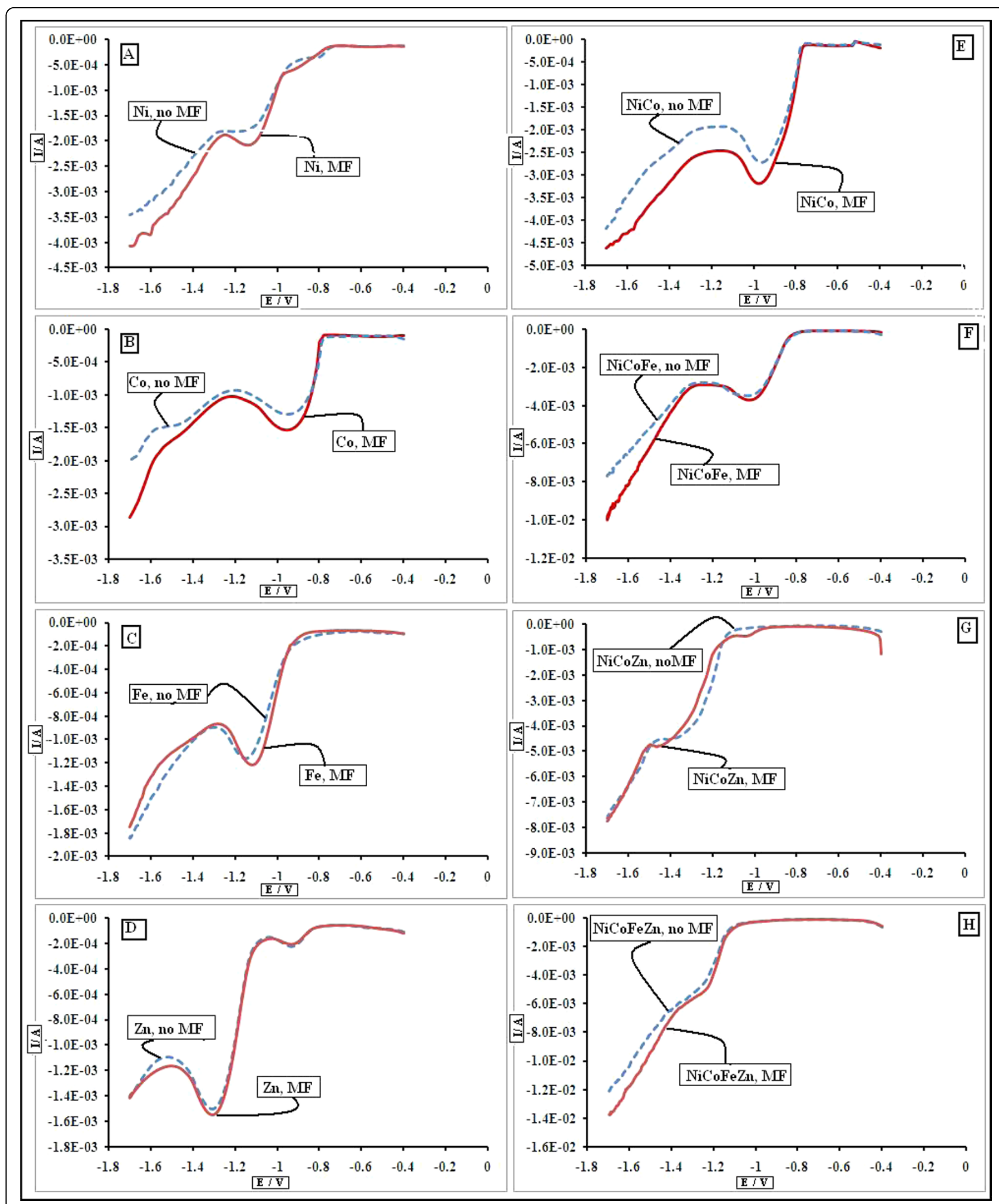

Figure 2 Voltammograms of; A) $\mathrm{Ni}^{2+}$; B) $\mathrm{Co}^{2+}$; C) $\mathrm{Fe}^{2+}$; D) $\mathrm{Zn}^{2+}$; E) $\mathrm{Ni}^{2+}, \mathrm{Co}^{2+}$; F) $\mathrm{Ni}^{2+}, \mathrm{Co}^{2+}, \mathrm{Fe}^{2+}$; G) $\mathrm{Ni}^{2+}, \mathrm{Co}^{2+}, \mathrm{Zn}^{2+} ; \mathrm{H}^{\mathrm{Ni}^{2+}}, \mathrm{Co}^{2+}, \mathrm{Fe}^{2+}$, $\mathrm{Zn}^{2+}$; from aqueous solution, with scan rate of $10 \mathrm{mV} \mathrm{s}^{-1}$ with the presence (solid line) and absence (dash line) of PPMF (9 T). When SCE and platinum wire were chosen as a reference and counter electrodes respectively. Concentration of each ions in solutions was $0.01 \mathrm{M}$. 
the strength of a magnetic field, D the diffusion constant, A the electrode surface area and $n$ the number of electrons involved in the electron transfer step.

Figures $2 \mathrm{C}$ and $2 \mathrm{~F}$ and Figures $2 \mathrm{D}$ and $2 \mathrm{H}$ confirms the theory of UPD where the electrodeposition of a less noble element shifts to more positive potentials for alloy electrodeposition compared to the electrodeposition of pure elements (i.e. $\mathrm{Zn}, \mathrm{Fe}$ ). Figure $2 \mathrm{C}$ shows the electroreduction of $\mathrm{Fe}^{2+}$ occurring at a peak of $-1.10 \mathrm{~V}$, and Fig. $2 \mathrm{~F}$ shows a peak at $-1.00 \mathrm{~V}$ for the $\mathrm{Ni}-\mathrm{Co}-\mathrm{Fe}$ alloy electrodeposition. Fig. 2D also shows the peak for $\mathrm{Zn}^{2+}$ electro-reduction occurring at $-1.30 \mathrm{~V}$, while Fig. $2 \mathrm{H}$ shows a wave at $-1.20 \mathrm{~V}$ for the $\mathrm{Ni}-\mathrm{Co}-\mathrm{Fe}-\mathrm{Zn}$ electrodeposition. This confirms Eq. 1, where an increase of the electro-reduction current in the voltammograms for the $\mathrm{Ni}-\mathrm{Co}-\mathrm{Fe}-\mathrm{Zn}$ alloy has taken place in the presence of a PPMF compared to without the PPMF.

Electrodeposition of $\mathrm{Ni}$-Co-Fe- $\mathrm{Zn}$ alloy layers were perform at chronoamperometric at various potentials $(-1.10,-1.20$ and $-1.30 \mathrm{~V})$ with and without the PPMF (9 T). Fig. 3 shows that the value of the limiting current $\left|j_{1}\right|$ is enhanced when the PPMF was applied. The increase in the limiting current is because of the magnetic-hydrodynamic (MHD) effect during the electrodeposition process. The electrodeposition mass also increased with the presence of the PPMF. The chronoamperogram in Fig. 3 illustrates the difference in current value $(\Delta \mathrm{I})$ with and without the PPMF (9 T), where $\Delta \mathrm{I}$ increases with the applied potential where: $\Delta \mathrm{I}$ for $-1.3 \mathrm{~V}>\Delta \mathrm{I}$ for -1.2 $\mathrm{V}>\Delta \mathrm{I}$ for $-1.1 \mathrm{~V}$. It is deduced that the Lorentz force $\left(\vec{F}_{L}\right)$ is larger with the increase of the current density due to the greater interaction between the electrical current and the magnetic flux $\left(\vec{F}_{L}=\vec{j} \times \vec{B}\right)$, and this increases the $\Delta \mathrm{I}$. The current increased from: 6.7 to 7.5 , 18 to 20 and 27 to $32 \mathrm{~mA}$ at potentials $-1.1 \mathrm{~V},-1.2 \mathrm{~V}$ and $-1.3 \mathrm{~V}$ respectively, for 2400 seconds duration, in

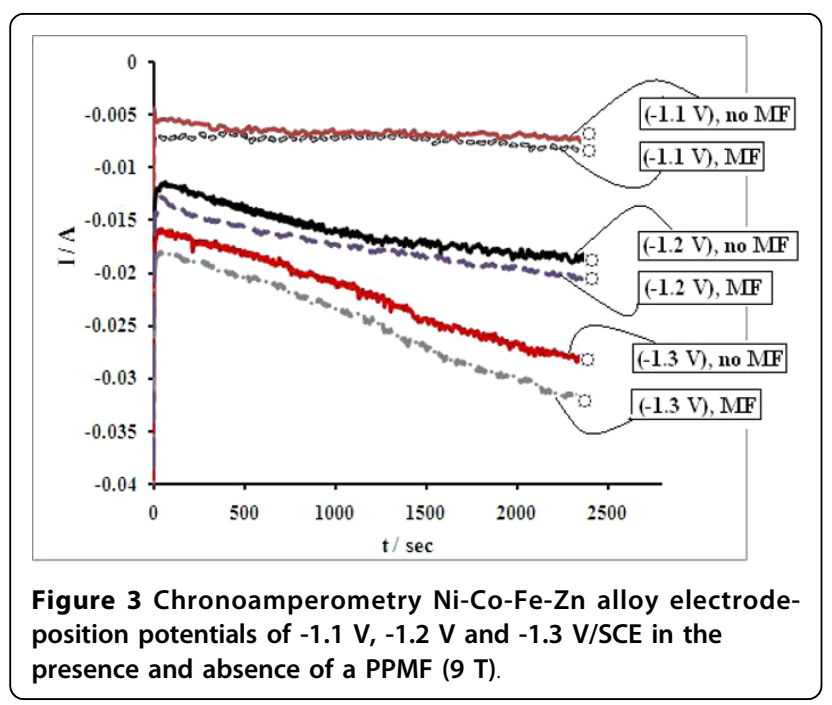

the marked points ( $\mathrm{a}$ ) in Fig. 3. The enhancement of the limiting current was calculated at the marked points as [19]:

$$
\text { Current enhancement } \Gamma \%=\frac{\Delta I}{I_{i}} \times 100
$$

where $\Delta \mathrm{I}$ is the current difference obtained with the presence and the absence of PPMF (9T) and $I_{i}$ is the current in the absence of PPMF. The percentage enhancement current $(\Gamma \%)$ was calculated as $(\Gamma \%=$ $11.9 \%, 16.7 \%$ and $18.5 \%)$ at $-1.1,-1.2$ and $-1.3 \mathrm{~V}$ respectively, for duration of 2400 seconds.

\section{Mass electrodeposition}

Figure 4 depicts the massogram of the $\mathrm{Ni}-\mathrm{Co}-\mathrm{Fe}-\mathrm{Zn}$ alloy electrodeposited layers calculated from the mass difference between the bare and coated $\mathrm{Cu}$ plates. The mass of electrodeposition increases with the increase of potential from -1.10 to $-1.30 \mathrm{~V}$. This phenomenon can be explained from the increase of the limiting current due to the decrease of diffusion layer thickness in the presence of PPMF [20,21]. As mentioned previously, it was shown that the mass electrodeposition quantity can be increased with the presence of the PPMF and the difference between mass deposition of alloys with and without a PPMF increases with more negative potential. Leventis et. al. [22] and Aboubi et. al. [23] have proven that the limiting current $\left(i_{l}\right)$ is proportional to the magnetic flux $B^{1 / 3}$, as given in Eq. 1 . Also, the relationship between the magnetic flux and mass increase due to decrease of the Nernst diffusion layer can be given as [22,23]:

$$
\mathrm{m} \approx 0.63(\rho \mathrm{R})^{-1 / 3} \cdot v^{-2 / 9} \cdot \mathrm{D}^{8 / 9} \cdot(\mathrm{nFcB})^{1 / 3}
$$

where $\rho$ is the solution density, $v$ the viscosity of solution, $\mathrm{D}$ the diffusion coefficient, $\mathrm{n}$ the number of

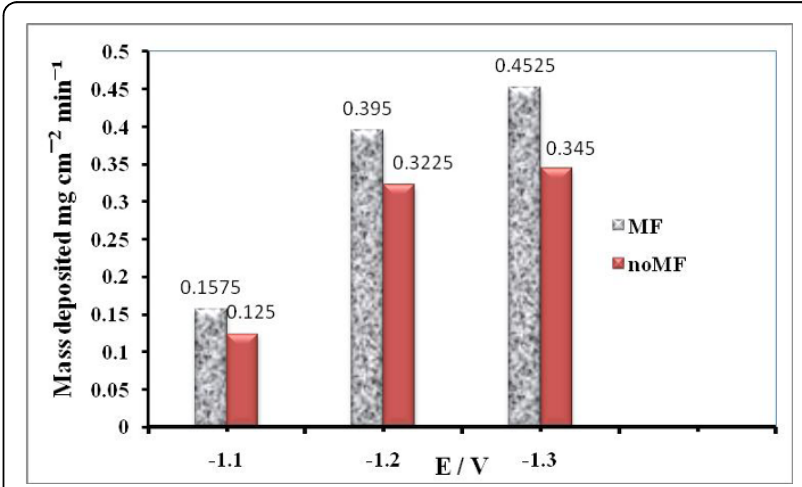

Figure 4 Mass of electrodeposition of Ni-Co-Fe- Zn alloys in the presence and absence of a PPMF when the SCE electrode was utilized. 
electrons per molecule, $\mathrm{C}$ the bulk concentration of electroactive species, $\beta$ the magnetic flux, $\mathrm{R}$ and $\mathrm{F}$ are the electrode radius and the Faraday constants respectively.

Fig. 4 depicts the mass electrodeposition under various current densities in the presence and absence of the PPMF, which also can be confirmed by Eq. 3 . The mass of the Ni-Co-Fe- $\mathrm{Zn}$ alloy electrodeposited layers were calculated from difference in mass before and after electrodeposition on the copper plates. Our previous results $[24,25]$ have also shown that the mass of the electrodeposited layers was greater with the PPMF than without. Furthermore as given in a previous section, the difference between of mass of electrodeposition in the presence and absence of the PPMF increases with the increase in the current. As the current increases, the Magneto-Hydrodynamic (MHD) effect becomes more pronounced due to the increase of Lorentz Force, where $\Delta \mathrm{m}=0.03$ to $0.107 \mathrm{mg} \mathrm{cm} \mathrm{min}^{-1}$ from Fig. 4 .

\section{SEM/EDX}

The surface morphology of the $\mathrm{Ni}-\mathrm{Co}-\mathrm{Fe}-\mathrm{Zn}$ electrodeposited films obtained from the chloride bath was investigated via Scanning Electron Microscopy (SEM). The SEM images 5 (A, C) and 5 (B, D) are films obtained at $-1.10 \mathrm{~V}$ and $-1.30 \mathrm{~V}$ respectively (Fig. 5). The right images $5 \mathrm{C}$ and $5 \mathrm{D}$ are layers electrodeposited with the presence of PPMF $(9 \mathrm{~T})$ while $5 \mathrm{~A}$ and $5 \mathrm{~B}$ were obtained from electrodeposits without PPMF. Several researchers $[26,27]$ have found that the magnetic field affects the morphology of the deposits. The morphology of the NiCo-Fe-Zn alloy shows nodular shape (with PPMF) for $5 \mathrm{C}$ compared to $5 \mathrm{~A}$ with polyhedral grains where both of them were deposited at $-1.10 \mathrm{~V}$. The SEM micrographs are accompanied by EDX graphs which indicate that all of them contain $\mathrm{Ni}, \mathrm{Co}, \mathrm{Fe}$ and $\mathrm{Zn}$ elements. The elemental composition of the galvanostatically deposited alloys was determined by EDX, illustrated in Fig. 6. It was found that the content of $\mathrm{Ni}$ in the electrodeposited layers is always lower than the composition reference line (CRL) due to the anomalous behaviour already discussed. The CRL of $\mathrm{Ni}$ is defined as [16];

$$
\mathrm{CRL}=\frac{c\left(\mathrm{Ni}^{2+}\right)}{\left[c\left(\mathrm{Ni}^{2+}+\mathrm{Co}^{2+}+\mathrm{Fe}^{2+} \mathrm{Zn}^{2+}\right)\right]} \times 100
$$

where $\mathrm{c}$ is the concentration of each ion (e. g. c $(\mathrm{Ni})$ is the concentration of $\mathrm{Ni}^{2+}$ in the electrolyte). According to the EDX results the \%wt $\mathrm{Zn}$ decreases with the increase of the current density due to the increase in applied potential. As shown in Fig. 6, referring to CRL, the anomalous behaviour is confirmed, particularly in the less noble element $\mathrm{Zn}$.

Notably, the lowest elemental content of the alloys belonged to $\mathrm{Fe}$, where the chemical oxidation of $\mathrm{Fe}^{2+}$ to the more stable $\mathrm{Fe}^{3+}$ takes place in the solution. Some

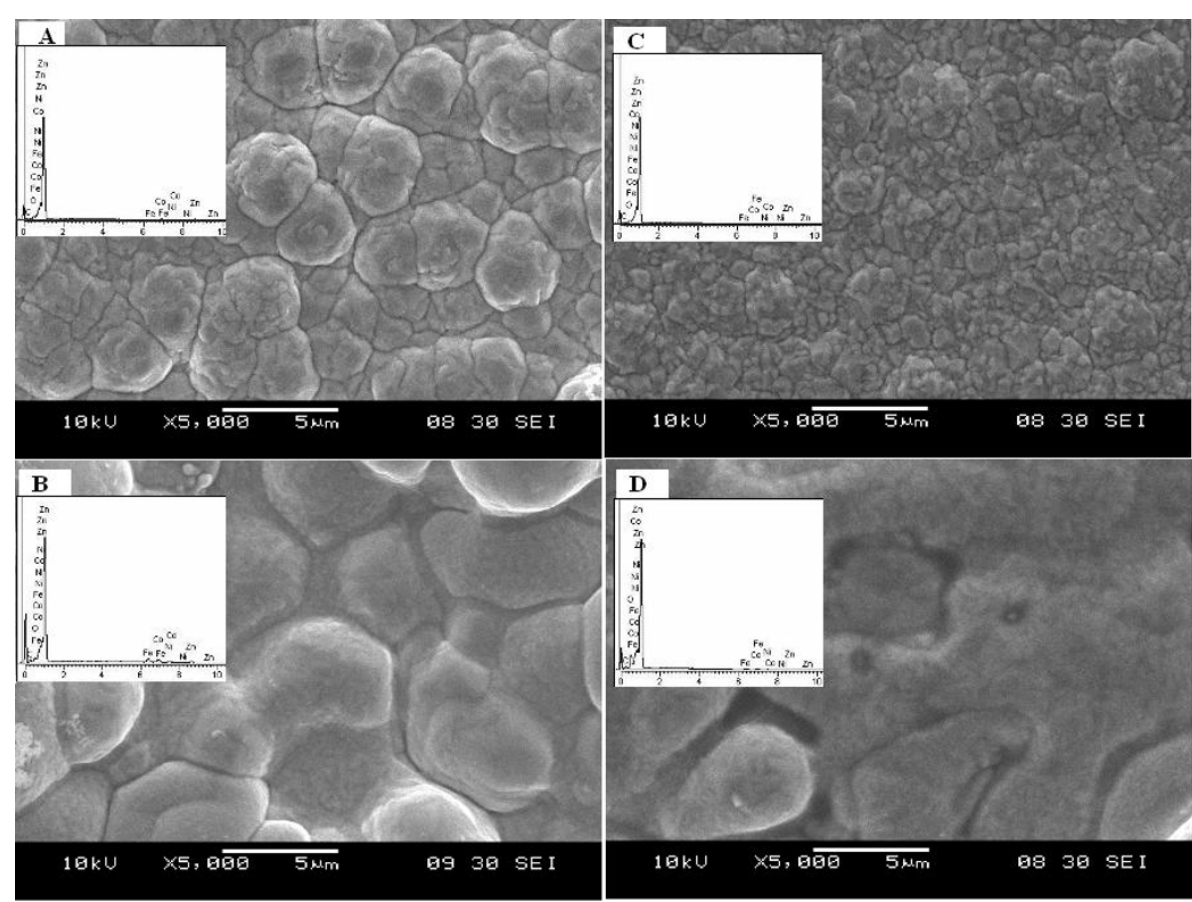

Figure 5 SEM micrographs (magnification 1000x) of Ni-Co-Fe-Zn alloy electrodeposited without PPMF: A) -1.1 V, B) -1.3 V, and with PPMF (9 T): C) $\mathbf{- 1 . 1}$ V, D) -1.3 V/SCE. Inset are the EDX spectrums. 


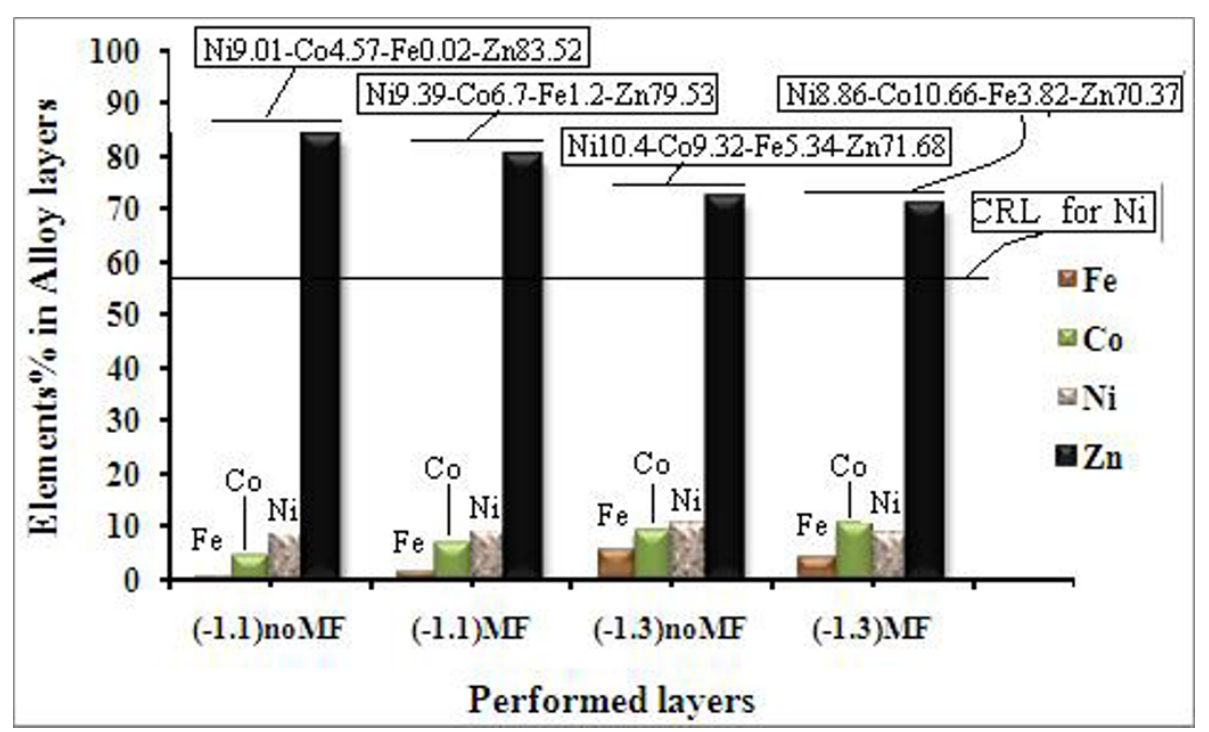

Figure 6 EDX results of the percentages of elements in Ni-Co-Fe-Zn alloys electrodeposited at potentials of $-1.1 \mathrm{~V}$ and $-1.3 \mathrm{~V} / \mathrm{SCE}$ with the absence and presence of PPMF, together with the total percentages of the elements in all four electrodeposited alloys. The CRL line of $\mathrm{Ni}$ is $57 \%$.

authors reported [16] that the co-electrodeposition of alloys with $\mathrm{Fe}^{2+}$ can take place by using citric acid or iron powder in the solution to avoid the precipitation of $\mathrm{Fe}(\mathrm{OH})_{3}$. In this work, the solution was free of any chelating reagent to prevent the oxidation of $\mathrm{Fe}^{2+}$ to $\mathrm{Fe}^{3+}$ leading to the lowest elemental content being $\mathrm{Fe}$ for the deposited layers. It is also noteworthy that the \%wt Co increases due to the increase of the applied potential and the applied PPMF compared to Ni because of the anomalous behaviour in Co electrodeposition.

\section{AFM studies}

Atomic force microscopy (AFM) was used to examine the surface roughness (RMS) of the Ni-Co-Fe- $\mathrm{Zn}$ alloys. Fig. 7 shows the 3D AFM images of the Ni-Co-Fe- Zn layers performed with and without PPMF $(9 \mathrm{~T})$. The 3D AFM images were prepared from a scanning surface of $5 \times 5 \mu \mathrm{m}$. The image layers $7 \mathrm{~A}$ and $7 \mathrm{C}$ were obtained at $-1.10 \mathrm{~V}$ potential from the electrodeposition bath. The image layers 7B and 7D were produced for the $\mathrm{Ni}-\mathrm{Co}-$ $\mathrm{Fe}-\mathrm{Zn}$ alloys at $-1.30 \mathrm{~V}$ potential from mixed metal ions in the electrodeposition solution. The 3D AFM images of alloy electrodeposited layers in the presence of a PPMF are on the right column (7C and 7D), and the 3D images of layers belonging to films that are fabricated without the magnetic field are on the left (7A and 7B). These images show that the rough surfaces are reduced for the layers electrodeposited with the presence of PPMF at the same operating condition. At the applied voltage of $-1.1 \mathrm{~V}$, the roughness factor was reduced from $48.5 \mathrm{~nm}$ (7A; without PPMF) to $23 \mathrm{~nm}$ (7C; with
PPMF). Furthermore, at the applied voltage of $-1.30 \mathrm{~V}$, the roughness factor was reduced from $112 \mathrm{~nm}$ (7B; without PPMF) to $39 \mathrm{~nm}$ (7D; with PPMF). Fahidy [28] has investigated the influence of a PPMF on the dendrites and branches of an electrodepositional surface, but the smoothness effect of an applied magnetic field on electrodeposition surface is still unclear.

Nikolic et. al. [29] suggested that an effective potential operates at dendrite formation causes a decrease of surface roughness with the presence of a magnetic field during electrodeposition. According to them, dendritic growth is suppressed with the increase in magnetic flux (B). They stated that the effective potential was reduced with application of a magnetic field at the end of the dendrites and effective potential $U_{\text {eff }}$ is given by:

$$
\mathrm{U}_{\mathrm{eff}}=\mathrm{U}_{\mathrm{c}}-\mathrm{IR}(\mathrm{B}=0,1)
$$

in the absence of the magnetic field and

$$
\mathrm{U}_{\mathrm{eff}}=\mathrm{U}_{\mathrm{c}}-\mathrm{IR}(\mathrm{B}=\mathrm{B} \circ, 1)
$$

in the presence of the magnetic field,

where $U_{\text {eff }}$ and $U c$ are effective and applied cathodic potentials, respectively, $\mathrm{I}$ is the deposition current and R is the resistance of dendrites (filaments) with 1 height. Subsequently, effective potential at the end of the dendrites was reduced with increasing magnetic flux (B). Eventually, the valley space of the electrodepositing surface will be filled with the depositing charged particles, and therefore a smoother surface results from the magneto-electrodeposition process. 



Figure 7 AFM images of Ni-Co-Fe-Zn alloy surface electrodeposited in the absence of PPMF: A) -1.1 V/SCE, B) $-1.3 \mathrm{~V} / \mathrm{SCE}$, and with PPMF (9 T): C) -1.1 V/SCE, D) -1.3 V/SCE. Layer obtained at: -1.1 V/SCE

\section{Conclusion}

The influence of the magnetic field (9 T) oriented parallel to the cathode surface for the electrodeposition of $\mathrm{Ni}-\mathrm{Co}-\mathrm{Fe}-\mathrm{Zn}$ alloys was studied at room temperature. The PPMF influence the electrochemical reaction by decreasing the double layer thickness and thus the current density and the mass deposition were increased. The increase of current was shown in the voltammograms in the presence of the PPMF (9T). The electrodeposition using chronoamperometry occurred at potentials $-1.1,-1.2$ and $-1.3 \mathrm{~V}$ for duration $2400 \mathrm{sec}$ with and without PPMF (9T). The increase in electrodeposition potential to more negative values correlated with the increase of the percentage of current enhancement $(\Gamma \%)$ with values $11.9 \%, 16.7 \%$ and $18.5 \%$ at -1.10 , -1.20 and $-1.30 \mathrm{~V}$ respectively, for $2400 \mathrm{sec}$, with the presence of PPMF. The surface roughness of the electrodeposited alloys was reduced with the presence of PPMF from $48.5 \mathrm{~nm}$ (Fig. 7A; without PPMF) to $23 \mathrm{~nm}$ (Fig. 7C; with PPMF) at $-1.1 \mathrm{~V}$ depositional potential. Furthermore, for deposition at potential $-1.3 \mathrm{~V}$, the roughness factor was reduced from $112 \mathrm{~nm}$ (7B; without PPMF) to $39 \mathrm{~nm}$ (7D; with PPMF).

\section{Abbreviations}

The abbreviations used in this paper are AFM: Atomic force microscopy; CRL: Composition Reference Line; EDX: Energy Dispersive X-Ray; HSM: Hydroxide
Suppression Mechanism; $\mathrm{K}_{\mathrm{sp}}$ : solubility constant; : Paramagnetic Force; : Field Gradient Force; : Lorentz Force; : Magnetic Damping Force; : Electrokinetic Force; MHD: Magneto-Hydrodynamic; PPMF: Permanent Parallel Magnetic Field; SEM: Scanning Electron Microscopy and UPD: Under Potential Deposition.

\section{Acknowledgements}

We would like to thank the University of Malaya for the financial support provided by university research grant PS 388/2008C, UMCiL grant (TA009/ 2008A) and (TA007/2009A). One of the authors (M. Ebadi) acknowledges the University of Malaya for his fellowship. Discussion with C. G. Jesudason is also acknowledged.

\section{Authors' contributions}

ME completed the laboratory work, data treatment and drafted the manuscript. YA and MRM data analysis. WJB coordinated the study, data analysis and edited the text. All authors have read and approved the final manuscript.

\section{Competing interests}

The authors declare that they have no competing interests.

Received: 11 March 2010 Accepted: 6 July 2010 Published: 6 July 2010

\section{References}

1. Brenner A: Electrodeposition of alloys: Principles and practice Vols 1 and 2. New York and London: Academic Press 1963.

2. Verberne Wim MJC: Zinc-Cobalt Alloy Electrodeposition. Trans Ins Met Finish 1986, 64(1):30-32.

3. Ohtsuka T, Komori A: Study of initial layer formation of Zn-Ni alloy electrodeposition by in situ ellipsometry. Electrochim Acta 1998, 43(2122):3269-3276

4. Akiyama $\mathrm{T}$, Fukushima $\mathrm{H}$ : Recent study on the mechanism of the electrodeposition of iron-group metal alloys. ISIJ International 1992, 32(7):787-798. 
5. Dahms H, Caroll IM: The Anomalous Codeposition of Iron-Nickel Alloys. J Electrochem Soc 1965, 112(8):771-775.

6. Higashi K, Fukushima H, Urakawa T, Adaniya T, Matsudo K: Mechanism of the electrodeposition of zinc alloys coating a small amount of cobalt. J Electrochem Soc 1981, 128(10):2081-2085.

7. Marikar YMF, Vasu KI: Ternary iron-cobalt-nickel alloy from the fluoborate bath part I. Deposition anode corrosion mechanism. Electrodep Sur Treat 1974, 2(4):281-294

8. Lodhi ZF, Tichelaar FD, Kwakernaak C, Mol JMC, Terryn H, de Wit JHW: Combined composition and morphology study of electrodeposited ZnCo and Zn-Co-Fe alloy coatings. Sur Coat Tec 2008, 202(12):2755-2764.

9. Lodhi ZF, Mol JMC, Hamer WJ, Terryn HA, De Wit JHW: Cathodic inhibition and anomalous electrodeposition of Zn-Co alloys. Electrochim Acta 2007, 52(17):5444-5452.

10. Chen Po-Yu, Sun I-Wen: Electrodeposition of cobalt and zinc-cobalt alloys from a lewis acidic zinc chloride-1-ethyl-3-methylimidazolium chloride molten salt. Electrochim Acta 2001, 46:1169-1177.

11. Roventi G, Fratesi R, Della Guardia RA, Barucca G: Normal and anomalous codeposition of $\mathrm{Zn}$ alloys from chloride bath. J App Electrochem 2000, 30(2):173-179.

12. Takahashi S, Aramata A, Nakamura M, Hasebe K, Taniguchi M, Taguchi S, Yamagishi A: Electrochemical and in situ STM studies of anomalous phosphate adsorption induced on $\mathrm{Zn}$ UPD at $\mathrm{Au}\left(\begin{array}{lll}1 & 1 & 1\end{array}\right)$ in the presence of halide ions in aqueous phosphate solutions. Sur Sci 2002, 512(12):37-47.

13. Fukushima H, Akiyama T, Higashi K, Kammel R, Karimkhani M: Electrodeposition behavior of binary zinc alloy with iron-group metals from sulfate baths. Int Conf on Zinc and Zinc Alloy Coated Steel SheetGALVATECH '89; Tokyo; Japan 1989, 5:45-50.

14. Nicol MJ, Philip HI: Underpotential deposition and its relation to the anomalous deposition of metals in alloys. J Electroanal Chem 1976, 70(2):233-237.

15. Swathirajan S: Electrodeposition of zinc + nickel alloy phases and electrochemical stripping studies of the anomalous codeposition of zinc. J Electroanal Chem 1987, 221(1-2):211-228.

16. Lodhi ZF, Mol JMC, Hovestad A, Terryn H, de Wit JHW: Electrodeposition of $\mathrm{Zn}$-Co and Zn-Co-Fe alloys from acidic chloride electrolytes. Sur Coat Tec 2007, 202(1):84-90.

17. Hinds G, Coey JMD, Lyons MEG: Influence of magnetic forces on electrochemical mass transport. Electrochem Comm 2001, 3:215-218.

18. Koza J, Uhlemann M, Gebert A, Schultz L, Schultz : The effect of magnetic field on the electrodeposition of iron. J Solid State Electrochem 2008, 12(2):181-192.

19. Tabakovic I, Riemer S, Vas'ko V, Spozhnikov V, Kief M: Effect of magnetic field on electrode reaction and properties of electrodeposited NiFe films. J Electrochem Soc 2003, 150:C635-C640.

20. Lioubashevski O, Katz E, Willner I: Effect of magnetic field directed orthogonally to surfaces on electrochemical process. J Phys Chem C 2007, 111:6024-6032.

21. Lioubashevski O, Katz E, Willner I: Magnetic field effect on electrochemical process: a theoretical hydrodynamic model. J Phys Chem C 2004, 108:5778-5784.

22. Leventis N, Chen MG, Gao XR, Canalas M, Zhang P: Electrochemistry with stationary disk and ring-disk millielectrodes in magnetic fields. J Phys Chem B 1998, 102:3512-3522.

23. Aaboubi O, Chopart JP, Douglade J, Oliver A, Gabrielli C, Tribollet: Electrochemical growth of iron arborescences under in-plane magnetic field: morphology symmetry breaking B. J Electrochem Soc 1990, 137:1796-1804.

24. Ebadi M, Basirun WJ, Alias Y: Influence of Magnetic Field on the Electrodeposition of Ni-Co Alloy. J Chem Sci 2009, 21(9):7354-7362

25. Ebadi M, Basirun WJ, Alias Y: Influence of magnetic field on the mass electrodeposition and investigation on corrosion rate in $\mathrm{Ni}$ and $\mathrm{Ni}-\mathrm{Co}$ alloy. Asian J Chem 2009, 21(8):6343-6353.

26. Ispas A, Matsushima $H$, Bund A, Bozzini B: Nucleation and growth of thin nickel layers under the influence of a magnetic field. Electrochim Acta 2009, 54(20):4668-4675.

27. Koza JA, Uhlemann M, Mickel C, Gebert A, Schultz L: The effect of magnetic field on the electrodeposition of CoFe alloys. J Mag Mag Mat 2009, 321(14):2265-2268.
28. Fahidy TZ: Characteristics of surface produced via magnetoelectrolytic deposition. Prog Sur Sci 2001, 68:155-188.

29. Nikolić ND, Wang H, Guerrero C, Ponizovskaya EV, Pan G, Garcia N: Magnetoresistance controls of arborous bead-dendritic growth of magnetic electrodeposits: Experimental and theoretical results. $J$ Electrochem Soc 2004, 151(9):C577-C584.

doi:10.1186/1752-153X-4-14

Cite this article as: Ebadi et al:: Electrodeposition of quaternary alloys in the presence of magnetic field. Chemistry Central Journal 2010 4:14.

\section{Publish with ChemistryCentral and every scientist can read your work free of charge \\ "Open access provides opportunities to our colleagues in other parts of the globe, by allowing anyone to view the content free of charge." \\ W. Jeffery Hurst, The Hershey Company.}

- available free of charge to the entire scientific community

- peer reviewed and published immediately upon acceptance

- cited in PubMed and archived on PubMed Central

- yours - you keep the copyright

Submit your manuscript here:

http://www.chemistrycentral.com/manuscript/<smiles>c1ccccc1</smiles>

Chemistry Central 